\title{
Article \\ Experimental Study of Explosion Mitigation by Deployed Metal Combined with Water Curtain
}

\author{
Thérèse Schunck *(D) and Dominique Eckenfels
}

Citation: Schunck, T.; Eckenfels, D. Experimental Study of Explosion Mitigation by Deployed Metal Combined with Water Curtain. Appl. Sci. 2021, 11, 6539. https://doi.org/ 10.3390/app11146539

Academic Editor: Ricardo Castedo

Received: 18 June 2021

Accepted: 14 July 2021

Published: 16 July 2021

Publisher's Note: MDPI stays neutral with regard to jurisdictional claims in published maps and institutional affiliations.

Copyright: (c) 2021 by the authors. Licensee MDPI, Basel, Switzerland. This article is an open access article distributed under the terms and conditions of the Creative Commons Attribution (CC BY) license (https:/ / creativecommons.org/licenses/by/ $4.0 /)$.
French-German Research Institute of Saint-Louis, ISL, 5 rue du Général Cassagnou, 68301 Saint-Louis, France; dominique.eckenfels@isl.eu

* Correspondence: therese.schunck@isl.eu; Tel.: +33-3-8969-5186

\begin{abstract}
In this paper, protective barriers made of perforated plates with or without a water cover were investigated. In urban areas, such barriers could be envisaged for the protection of facades. An explosive-driven shock tube, combined with a retroreflective shadowgraph technique, was used to visualize the interaction of a blast wave profile with one or two plates made of expanded metal. Free-field air blast experiments were performed in order to evaluate the solution under real conditions. Configurations with either one or two grids were investigated. The transmitted pressure was measured on a wall placed behind the plate(s). It was observed that the overpressure and the impulse downstream of the plate(s) were reduced and that the mitigation performance increased with the number of plates. Adding a water layer on one grid contributed to enhance its mitigation capacity. In the setup with two plates, the addition of a water cover on the first grid induced only a modest improvement. This blast mitigation solution seems interesting for protection purposes.
\end{abstract}

Keywords: blast; mitigation; grid; water curtain

\section{Introduction}

The protection of people and structures against the effects of blast waves from terrorist attacks or industrial hazards is of significant interest. It is well known that protective barriers are an effective way to reduce blast loads and to mitigate the adverse effects. Protective solid barriers are usually made of reinforced concrete, concrete masonry unit or steel-concrete-steel composite materials. These barriers are very rigid and have negligible deformation. In urban areas, other protective barriers could be envisaged for facades. The blast wave would be absorbed, deflected or disrupted to be ultimately reduced before it reaches its intended target. Perforated plates disrupt blast waves: it has been shown that grids or perforated plates modify the flow field by introducing new shock waves, regions of vortices and considerable turbulence in which the energy of the incident shock wave can be dissipated [1-3]. Moreover, grids or perforated plates could be modern architectural design elements which can be used outside buildings. The use of water walls for mitigating the damages from blast waves generated by an explosion has also been described [4], although there is only limited literature on this topic. It seems that the mitigation stems from the fact that the blast wave is obstructed, reflected and diffracted by the water wall. Consequently, it could be an advantage to add a water cover to the grids or perforated plates in order to protect building façades or walls.

Recently, the shock wave attenuation performance of protective barriers made of woven wire mesh was investigated [5]. The woven wire mesh was located about $5 \mathrm{~m}$ in front of a wall and no obvious mitigation was observed behind the barrier. The woven wire mesh had a very high porosity and this probably explains such results. Two previous studies have been published regarding metal ring meshes, grids or perforated plates combined with a downward-streaming water curtain for blast mitigation [6,7]. Gebbeken et al. [6] tested a stainless steel ring mesh in combination with a flowing water layer. The charges were detonated $5 \mathrm{~m}$ in front of the ring mesh with or without a water cover and the side-on 
overpressure was measured on the shock wave path. The reflected overpressure was also measured on a wall located $5 \mathrm{~m}$ behind the ring mesh. For the ring mesh alone, they described an initial side-on overpressure reduction of approximately $17 \%$ at $50 \mathrm{~cm}$ behind the grid and of around 1-6\% at 1.5-2.5 m behind the grid. When the ring mesh was covered by water, the initial side-on overpressure was reduced by $56 \%$ close behind the ring mesh and by $20 \% 5 \mathrm{~m}$ behind the mesh. As regards the positive impulse, the ring mesh itself caused no reduction. However, a reduction of about $17-31 \%$ was obtained behind the mesh by adding a water curtain. The reflected pressure on the wall was slightly decreased by the ring mesh but the addition of a water cover did not improve the attenuation performance. In the second study [7], a transonic shock tube was used to visualize the interaction of a blast wave profile with a metallic perforated plate or with a metallic perforated plate covered by a layer of water. Free-field air blast experiments were also performed. Three grid types with different porosities were tested. The highest attenuation was obtained with the grid having the lowest porosity. The attenuation was of the order of $17-25 \% 25 \mathrm{~cm}$ downstream from the grid and about 25-30\% $3 \mathrm{~m}$ downstream from the grid. When the grids were covered by a water layer, the initial overpressure behind the plate was reduced for all grid types. The blast mitigation was improved, especially with the grids having a high porosity. Again, the most pronounced reduction (about 35 to $48 \%$ ) was obtained with the grid having the lowest porosity. The initial overpressure $3 \mathrm{~m}$ downstream was also reduced by about 20-30\%. The impulse was also reduced by the grids with or without a water film cover. Consequently, this blast mitigation method appears promising but still needs some further work and improvement. The porosity of the plate is an important factor to take into account in the blast mitigation performance and a water cover on the plate increases even more the blast attenuation. The plate should have a relatively low porosity. The use of a configuration with two plates could also represent an option for improvement. Indeed, it has been shown that shock wave trapping between two perforated plates enhanced the shock wave attenuation downstream from the grids [8].

In this paper, the assessment of this blast mitigation solution made of perforated plates with or without a water cover was further investigated in order to have a better understanding of its mechanism and to improve its performance. Grids made of expanded metal, with or without a water film, served as an obstacle. Expanded metal has an interesting geometry that enhanced the reflection of the shock wave, and a low porosity. First, an explosive-driven shock tube (EDST) was used to visualize the interaction of a blast wave profile with one or two plates made of expanded metal, using a retroreflective shadowgraph technique. Indeed, the propagation of blast waves in complex media is an important topic of shock wave research and there is a need to study wave phenomena in complex environments. EDSTs generates high dynamic loadings compared to conventional shock tubes. Their mitigation capacity could be assessed under a load comparable to that produced by several kilos of high explosives, located several meters from a target. Secondly, free-field air blast experiments were performed in order to evaluate the protection system under real conditions. Configurations with either one or two grids were investigated. The case in which a film of water was added on the grid, or on the first grid in the case of a two-grid configuration, was also studied. The transmitted pressure was measured on a wall placed behind the plate(s) and the shock wave reflection by the plate was assessed using a sensor located on the ground in front of the first grid.

\section{Materials and Methods}

\subsection{Samples}

Grids made of expanded metal were investigated (Figure 1). Expanded metal is a metal sheet that has been cut and stretched to form a regular pattern. Expanded metal is stronger than an equivalent weight of wire mesh because the material is deformed, allowing the metal to remain as a single piece. The expanded metal used in the present study had a hexagonal mesh. The characteristics were an open area of $24 \%$, a hole size 
of $45 \mathrm{~mm} \times 13 \mathrm{~mm}$, a thickness of $3 \mathrm{~mm}$, an apparent thickness of $9 \mathrm{~mm}$ and a strand of $5 \mathrm{~mm}$.

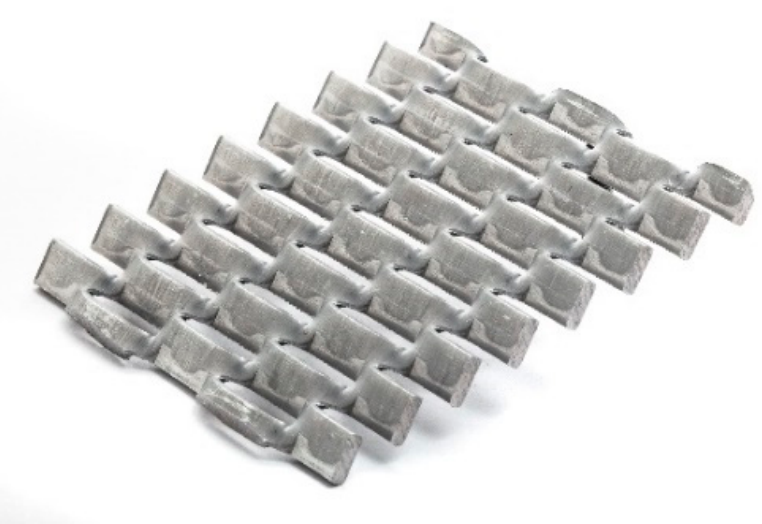

(a)

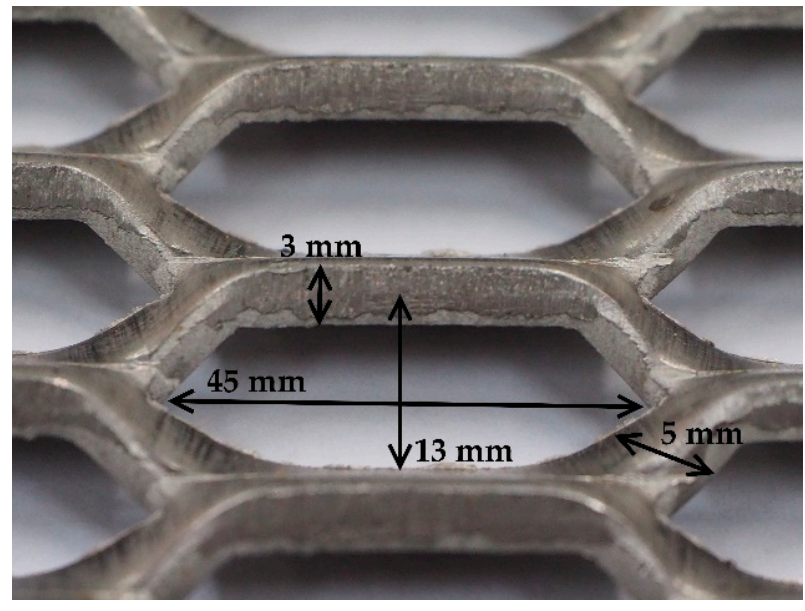

(b)

Figure 1. (a) Piece of expanded metal; (b) detail: open area of $24 \%$, hole size of $45 \mathrm{~mm} \times 13 \mathrm{~mm}$, thickness of $3 \mathrm{~mm}$, apparent thickness of $9 \mathrm{~mm}$, strand of $5 \mathrm{~mm}$.

\subsection{Explosive Driven Shock Tube}

The EDST was based on previously published works $[9,10]$. The shock tube has a square external section of $100 \mathrm{~mm} \times 100 \mathrm{~mm}$, a square internal section of $80 \mathrm{~mm} \times 80 \mathrm{~mm}$ and a total length of $1750 \mathrm{~mm}$ (Figure 2). A pressure sensor (Kulite HKS 375) was used to measure the reflected pressure at a wall behind the plates. A spherical charge of $\mathrm{C} 4$ was used $(\mathrm{m}=15 \mathrm{~g})$ to produce a planar blast wave. All the charges were cast and detonated, without any container, $50 \mathrm{~mm}$ from the shock tube inlet (Figure 2). A part of the initial spherical blast wave enters in the tube. At the tube inlet, the surface of the incident shock has a square curved shape which will be flattened as the shock travels through the tube. The initial spherical blast wave becomes almost completely planar after about $1.5 \mathrm{~m}$ of propagation, leading to an initial uniform loading at the outlet of the shock tube. The blast profile obtained in this way is realistic and in line with real threats.

The distance between the outlet of the EDST and the wall was $180 \mathrm{~mm}$. The plate, or the last plate in the case of two plates, was positioned $50 \mathrm{~mm}$ in front of the wall. Where two plates were used, the spacing between the plates was $40 \mathrm{~mm}$. The grid holes were always aligned directionally.

\subsection{Imaging for EDST}

A high speed Photron SA-Z camera was used to record images of the propagation and of the interaction of the shock wave with the plate(s) using a retroreflective shadowgraph technique [11]. An extreme high power light emitting diode (LED) (XHP70.2, CREE), located on an axis with the center of the camera lens, illuminated the outlet of the EDST and a panel covered by a retroreflective material (3M Reflexfolie 4090) which was placed in the background. Figure 3 shows a photograph of the camera with the LED and the EDST and the Figure 2 shows the position of the retroreflective panel relative to the EDST and the camera. A power supply and a purpose-built trigger unit allowed the LED to be pulsed for about $10 \mathrm{~ms}$. The reflection and the transmission patterns of the shock wave through the obstacle could be visualized via their shadow on the panel. Moreover, a piece of retroreflective material was plastered on the wall and a 45-degree inclined mirror was attached to the end of the EDST (Figure 4). The camera filmed the panel placed in the background but also the mirror, allowing for the visualization of the shock wave in the 
axial direction. The videos were recorded with a frame rate of 100,000 fps at a resolution of $408 \times 384$ pixels.

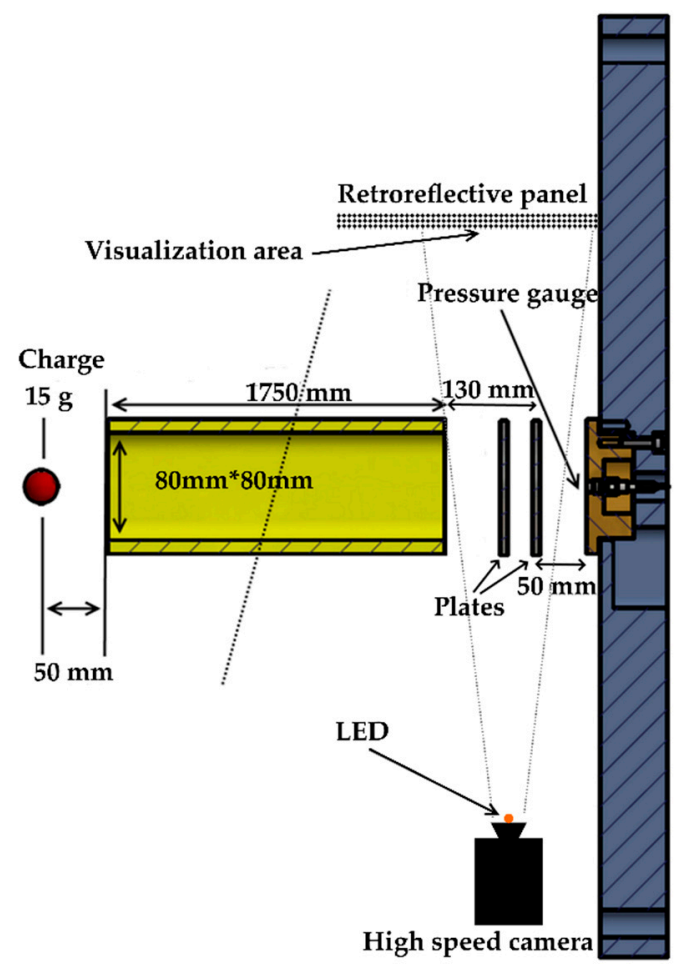

Figure 2. Schematic view of the explosive-driven shock tube and positioning of the pressure sensor and plates. The position of the high speed camera and of the retroreflective panel is also shown.

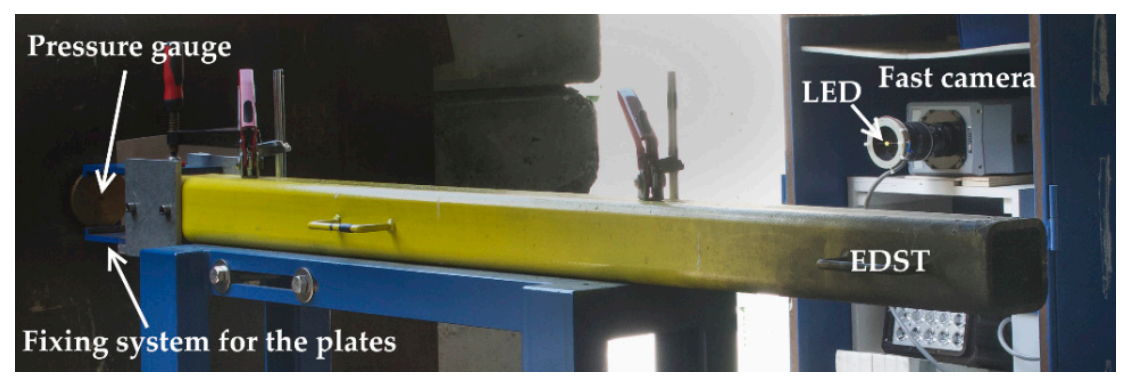

Figure 3. View of the experimental setup, showing the explosive driven shock tube and the high speed camera with the LED.

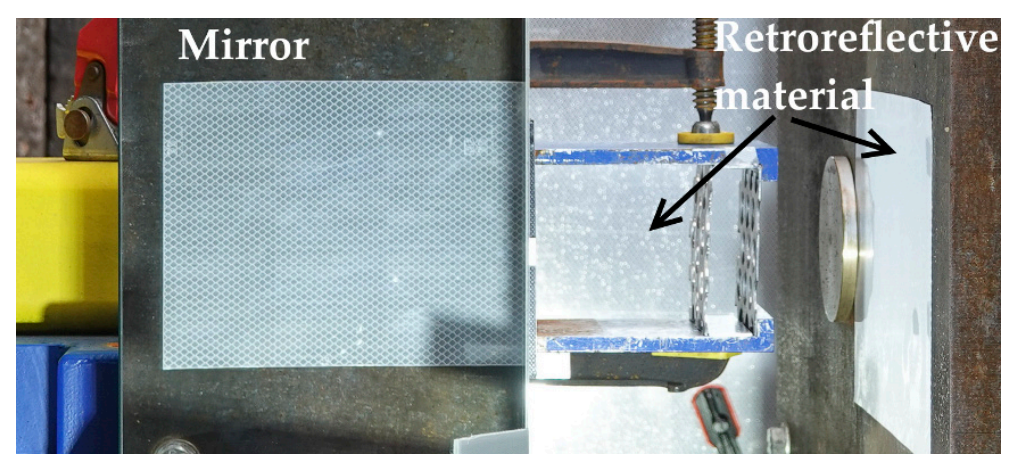

Figure 4. View of the EDST end showing the panel in the background, the piece of retroreflective material plastered on the wall and the 45 -degree inclined mirror. 


\subsection{Free Field}

Explosion tests were conducted with spheres of $2 \mathrm{~kg} \mathrm{C} 4$. The charges were raised by $25 \mathrm{~cm}$ and ignited by a high voltage cap (RP 501) (Figure 5). Configurations with either one or two grids were investigated. The addition of a film of water on the grid, or on the first grid in the case of a two-grid configuration, was also tested. For tests with one grid, the charge was positioned $3.8 \mathrm{~m}$ from the grid and $4.8 \mathrm{~m}$ from the wall (Figure 6). For tests with two grids, the charge was positioned $3 \mathrm{~m}$ from the first grid, $3.8 \mathrm{~m}$ from the second one and $4.8 \mathrm{~m}$ from the wall (Figure 5). When paired, grids were spaced $0.8 \mathrm{~m}$ apart. The grid size was $2 \mathrm{~m} \times 3 \mathrm{~m}$ and concrete blocks placed at the left and right of the grids were used to mount them (Figures 5 and 6). Each had the following dimensions: length $160 \mathrm{~cm}$, height $40 \mathrm{~cm}$ and width $80 \mathrm{~cm}$. One side-on pressure gauge (PCB137A23) (Figure 5), located at a right angle to the shock wave's propagation toward the wall, allowed for verification of reproducibility. One PCB sensor (M102A) was used to evaluate the effect of the grids or, of the grids covered by a film of water, of the reflected pressure on the wall located behind the grid (Figure 7, left). The sensor was positioned at a height of $50 \mathrm{~cm}$. One pressure gauge (M102A) was positioned on the ground in front of the first grid position (Figures 5-7, left). This gauge was located $19.5 \mathrm{~cm}$ from the first grid. The height of this gauge was $5 \mathrm{~cm}$. The water layer was generated by a pool fountain (VidalXL) (Figure 8).

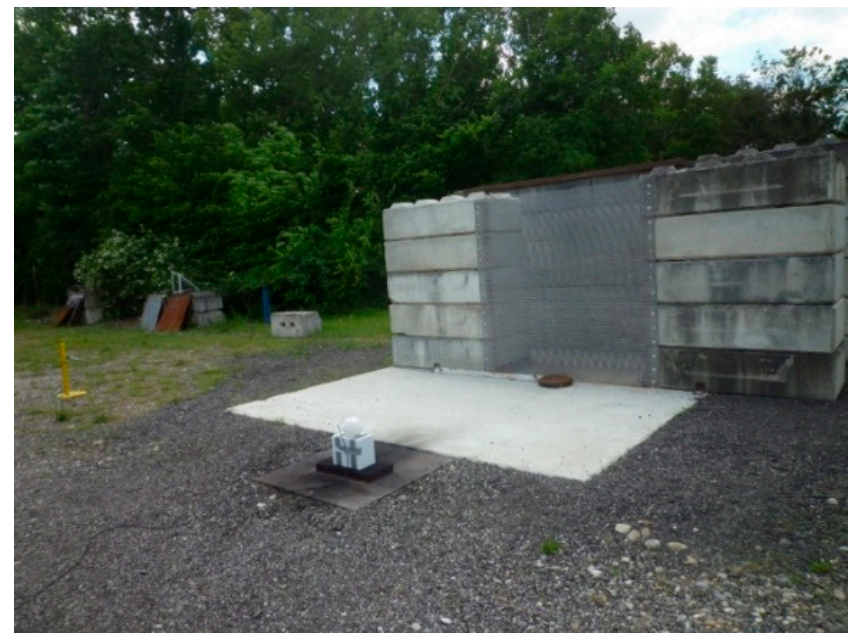

(a)

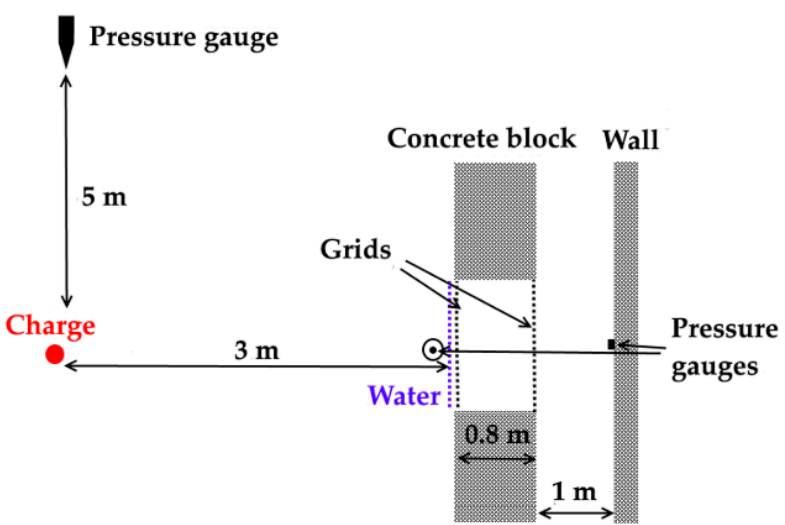

Concrete block

(b)

Figure 5. (a) Photography of the experimental setup; (b) Schematic diagram showing the charge, grids, concrete blocks, gauge in front of the grid and one side-on pressure gauge, placed at a right angle.

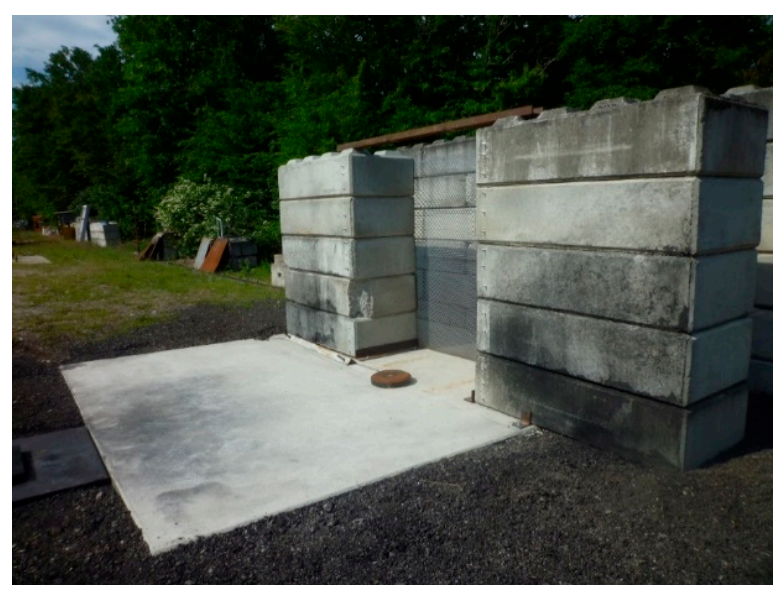

Figure 6. View of the experimental setup showing the one-grid configuration: the grid position, concrete blocks and gauge in front of the grid. 


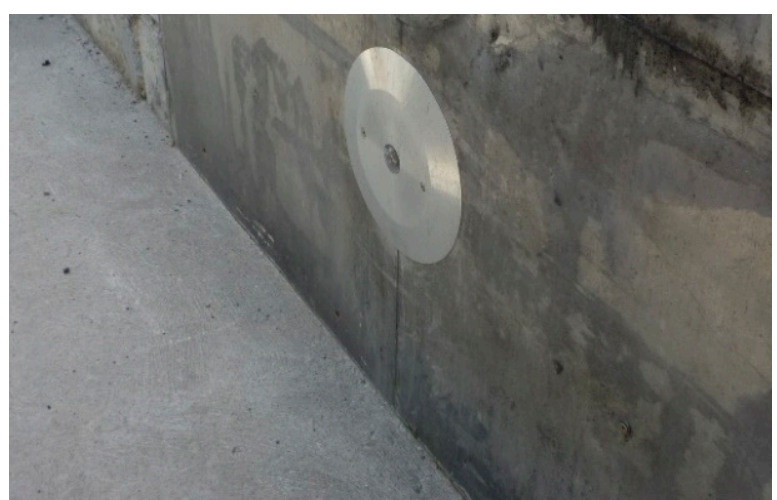

(a)

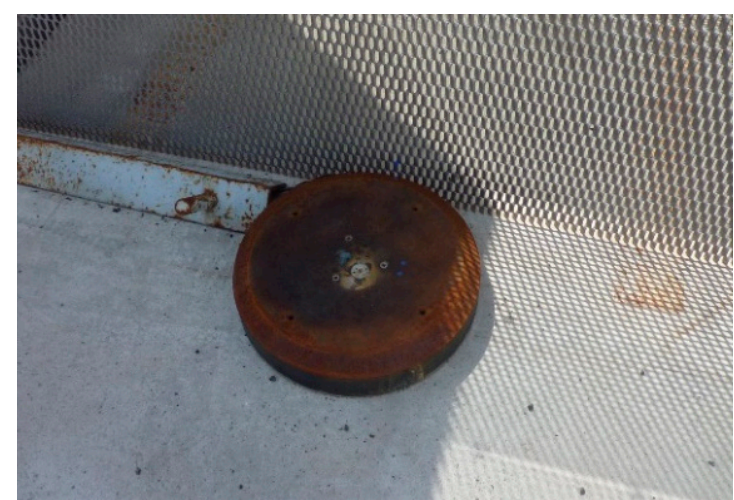

(b)

Figure 7. (a) Reflected pressure gauge located on the wall behind the grids; (b) pressure gauge located in front of the first grid position.

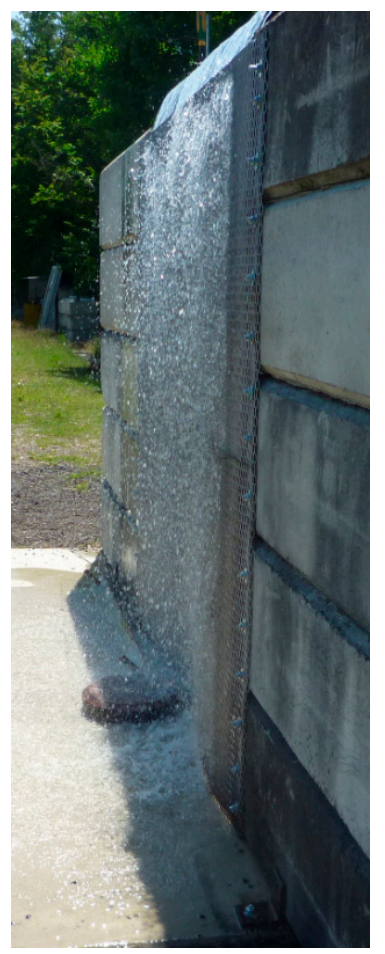

Figure 8. First grid equipped with a pool fountain.

\section{Results}

\subsection{Explosive Driven Shock Tube}

Figure 9 shows the shock wave propagating at the outlet of the EDST when there was no perforated plate. The photographs were taken with high-speed imaging. Thanks to the mirror, set at $45^{\circ}$ in front of the camera, imagery could be obtained from the axial direction simultaneously with the direct view. Consequently, events happening axially to the EDST outlet could be observed. The shock wave was not totally planar at the outlet of the tube; indeed, the two metallic plates, fixed parallel to the EDST at the end and which were used to clamp the perforated plates, reflected the shock wave $(t=1440 \mu \mathrm{s})$. These two plates had a shoulder at their ends which provided additional thrust for the fixation of the perforated plates. These shoulders can be seen in Figure 4 and the shock wave visibly interacts with them $(t=1520 \mu \mathrm{s})$. The shock wave emerging laterally from the EDST was visible in the mirror. It should be noted that the shock wave exited the EDST outlet immediately, but in the beginning the optical setup did not allow the observation of this expansion. 


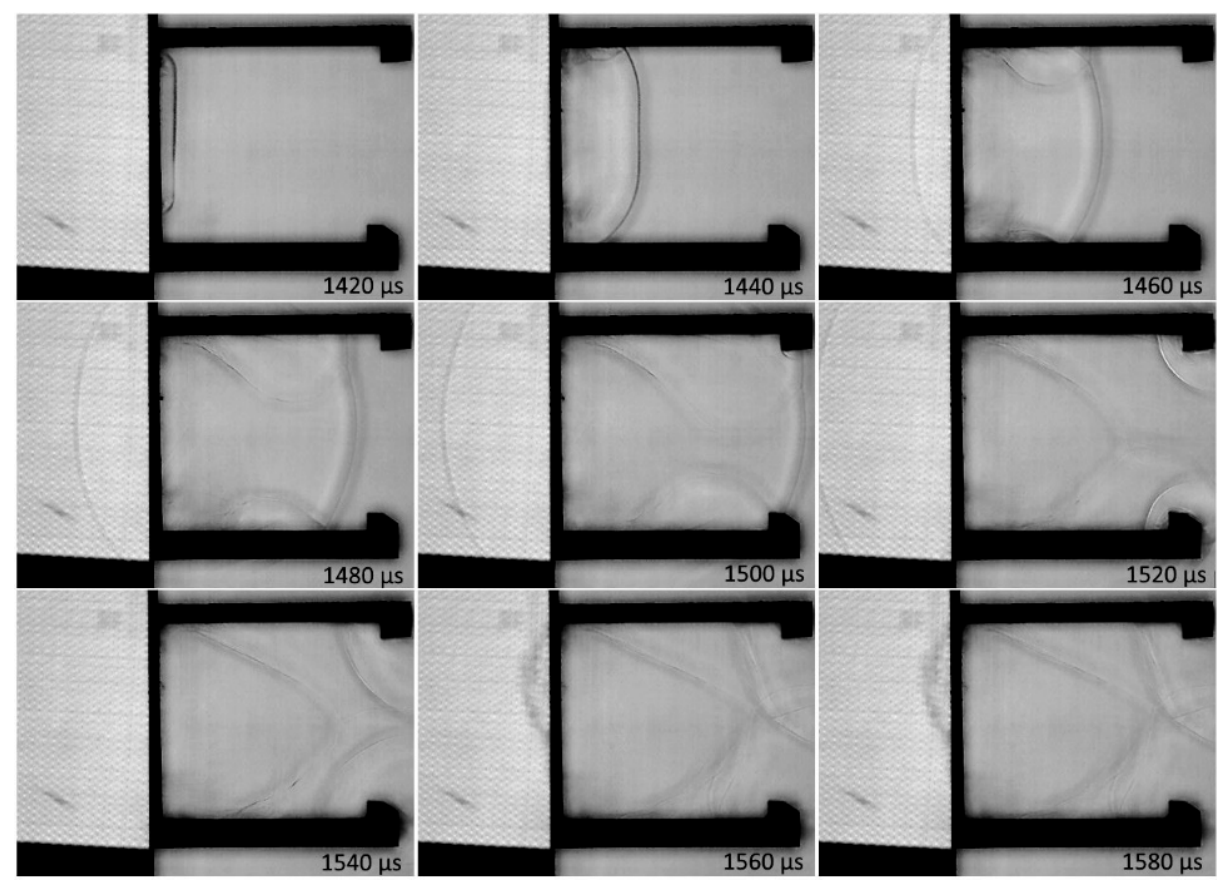

Figure 9. Photographic results of high-speed video recording, showing shock wave propagation at the outlet of the EDST ( $20 \mu$ s between each photograph).

Figure 10 shows shock wave propagation through one deployed metal plate. The plate was positioned at a distance of $130 \mathrm{~mm}$ from the tube outlet and at a distance of $50 \mathrm{~mm}$ in front of the wall. At $t=1470 \mu \mathrm{s}$, the shock wave when passing through the plate apertures split into several shock waves, one for each aperture, and these shock waves recombined further down. At $t=1530 \mu \mathrm{s}$, the shock wave behind the plate became almost planar again. A complex structure of turbulence appeared just behind the grid and it persisted for some time; at $\mathrm{t}=1510 \mu$ s turbulence began to form along the backside the grid, and at $t=1790 \mu$ s it was still observable. The reconbinated shock wave behind the perforated plate hit the wall and was reflected at $t=1570 \mu \mathrm{s}$. The remaining shock wave, which did not pass through the grid and was reflected by it, became almost planar at $\mathrm{t}=1550 \mu \mathrm{s}$.

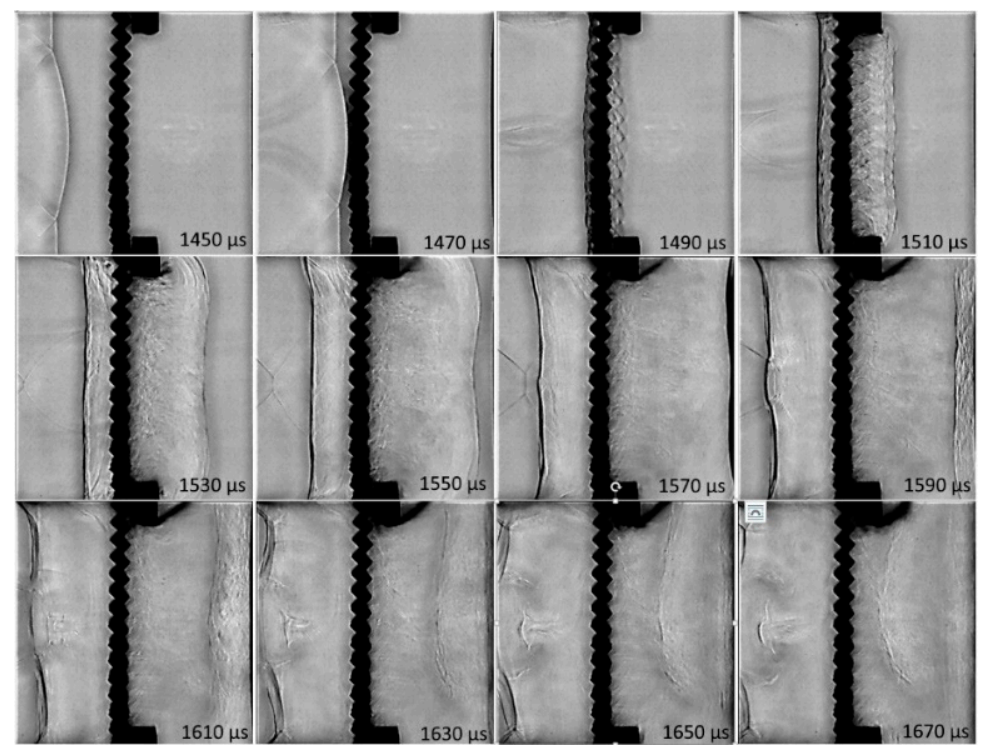

Figure 10. Photographic results of high-speed video recording, showing shock wave propagation through one plate of deployed metal ( $20 \mu$ s between each photograph). 
Figure 11 shows shock wave propagation through two deployed metal plates. The first plate was positioned at a distance of $90 \mathrm{~mm}$ from the tube outlet and at a distance of $90 \mathrm{~mm}$ in front of the wall. Grids were paired $40 \mathrm{~mm}$ apart. When passing through the apertures of the first plate $(t=1450 \mu \mathrm{s})$, the shock wave split into several shock waves, one for each aperture, and these shock waves recombined further down. The transmitted shock wave was similar to the incident shock wave at $t=1490 \mu \mathrm{s}$. At the back of the shock wave, between the two plates, lasting turbulence could be observed, especially immediately behind the first plate. The remaining shock wave, which did not pass through the first plate, was reflected, leading to the pattern captured at the back of this plate. Thereafter, the shock wave transmitted by the first plate impacted the second plate $(t=1510 \mu \mathrm{s})$ and, once again, a part of the shock wave was transmitted and part was reflected. The wave reflected by the second plate propagated toward the first plate and, as it arrived near the plate, the shock front and the turbulence became less obvious. We could also see turbulence behind the second plate.

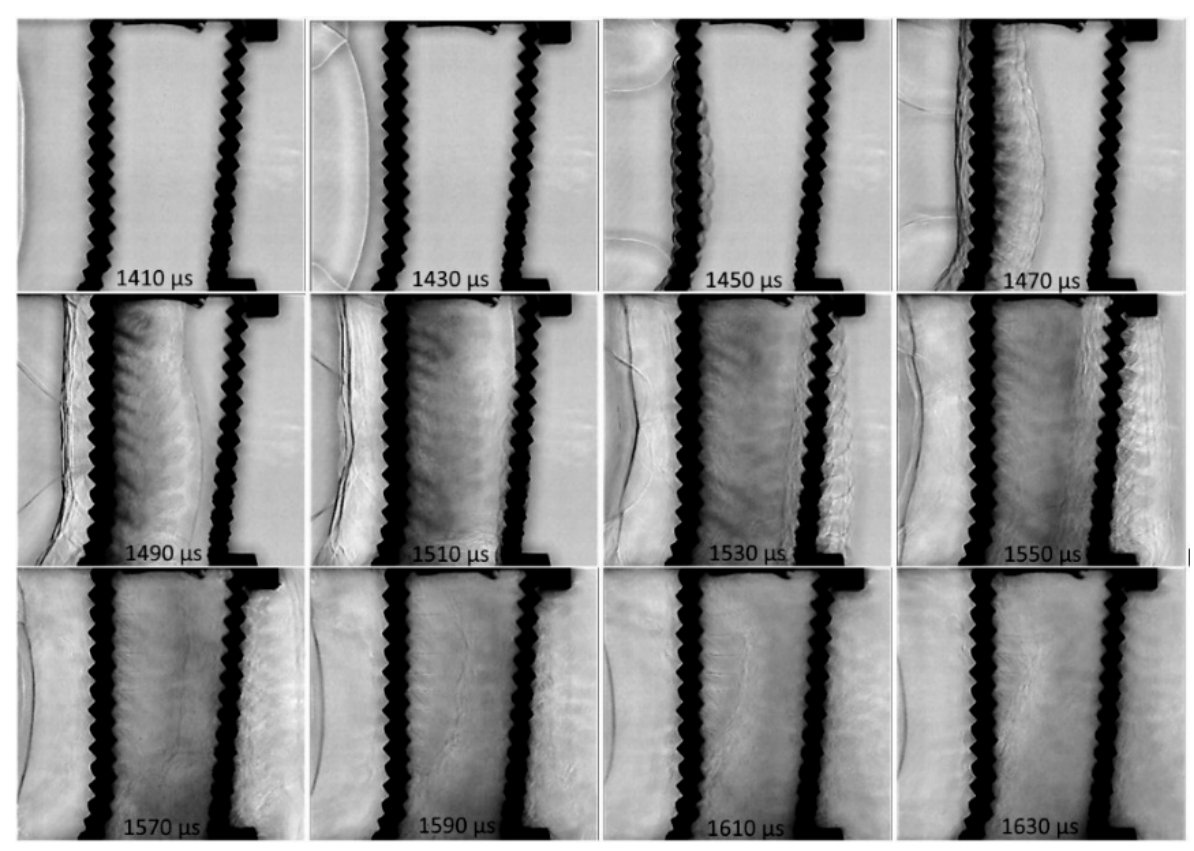

Figure 11. Photographic results of high-speed video recording, showing shock wave propagation through one plate of deployed metal ( $20 \mu$ s between each photograph).

Five reference tests were conducted without any plates and seven experiments were conducted with either one or two grids positioned at the outlet of the EDST. The reflected overpressure versus time was collected by the sensor inserted in the wall behind the plate. The blast wave propagation through the shock tube was computed with Autodyn (ANSYS) and the overpressure at the outlet of the shock tube was obtained. The calculated initial overpressure was 32 bar. The measured value at a distance of $180 \mathrm{~mm}$ was 18 bar, which was consistent with simulation. The impulse, which is the pressure signal integrated over time, as a function of time, was also computed. Figure 12a presents the reflected pressure as a function of time, obtained in a reference test and in one test each using one or two expanded metal plates. When the number of plates increased, the reduction of the initial reflected overpressure increased. The initial overpressure reflected on the wall was reduced by $46 \%$ and $72 \%$, respectively, when either one or two plates were positioned in front of the EDST (Table 1). Correspondingly, the maximum impulse was reduced by 68 and $89 \%$ (Table 1). 


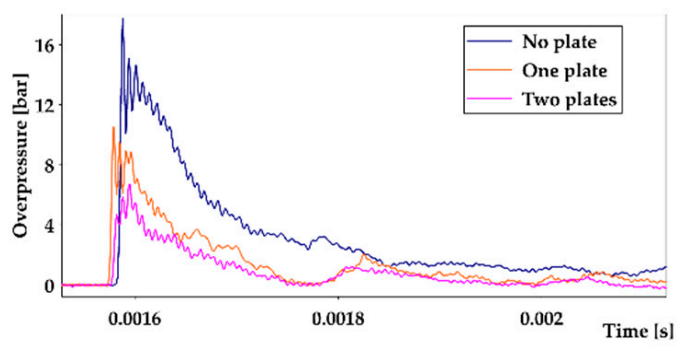

(a)

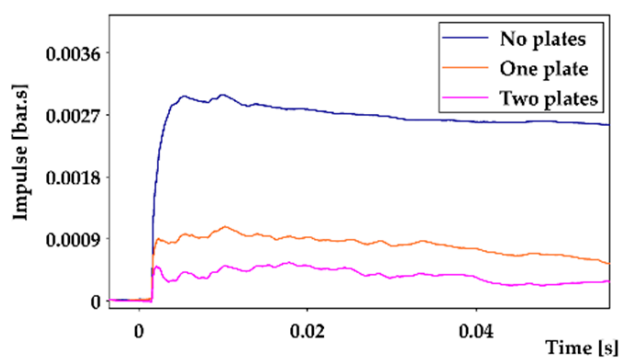

(b)

Figure 12. Reflected pressure (a) and impulse (b) measured on the wall positioned $50 \mathrm{~mm}$ behind either one or two expanded metal plates. One reference test, which was performed without plates, is also shown.

Table 1. Initial reflected overpressure and maximum impulse collected by the sensor inserted in the wall and located $50 \mathrm{~mm}$ downstream from the perforated plates for all experiments. The difference from the mean value obtained with the reference tests (no plate) is also given.

\begin{tabular}{cccccc}
\hline Type of Plate & Number of Plates & Overpressure (Bar) & Attenuation (\%) & Impulse (Bar-s) & Attenuation (\%) \\
\hline no plate & - & 22.82 & - & 0.0032 & - \\
no plate & - & 19.48 & - & 0.0040 & - \\
no plate & - & 15.61 & - & 0.0035 & - \\
no plate & - & 15.65 & - & 0.0037 & - \\
no plate & - & 15.73 & - & 0.0034 & - \\
expanded metal & 1 & 9.36 & 48 & 0.0011 & 70 \\
expanded metal & 1 & 7.71 & 57 & 0.0012 & 6.0013 \\
expanded metal & 1 & 10.89 & 39 & 0.0015 & 63 \\
expanded metal & 1 & 10.30 & 72 & 0.0003 & 59 \\
expanded metal & 2 & 4.46 & 75 & 0.0005 & 93 \\
expanded metal & 2 & 4.50 & 67 & 0.0005 & 87 \\
expanded metal & 2 & 5.86 & 75 & 0.0003 & 87 \\
expanded metal & 2 & 4.46 & & & 93 \\
\hline
\end{tabular}

\subsection{Free Field}

The initial overpressure and the maximum impulse obtained through the control gauge for all experiments are presented in Tables 2 and 3, respectively. These measurements showed that there was rather good reproducibility. The side-on overpressure was estimated with Kingery's and Bulmash's formula [12]. The detonation of $2 \mathrm{~kg}$ of C4 generates an overpressure of 0.8 bar at a distance of $5 \mathrm{~m}$. The measured values were consistent with this value. Figure 13 presents the overpressure measured on the wall for one test of each configuration. Two or three experiments were conducted for each configuration. Table 2 gives the initial overpressure value obtained in all the tests. According to Kingery's and Bulmash's formula [12], the detonation of $2 \mathrm{~kg}$ of $\mathrm{C} 4$ generates a reflected overpressure of $2.6 \mathrm{bar}$ at a distance of $4.8 \mathrm{~m}$. The measured values were consistent with this value. The overpressure was reduced when one plate was located in front of the wall, in the order of $32-47 \%$. Adding a second plate on the shock wave path led to a stronger attenuation. The initial overpressure was reduced by about $62-66 \%$. When a water film was used, the reflected overpressure on the wall was reduced even more, especially in the case of the one-plate configuration. The reduction of overpressure was about $69-71 \%$ and $66-74 \%$ for one-plate configurations and two-plate configurations, respectively. The setup using a water wall alone was also evaluated and the reflected overpressure on the wall was not modified. Figure 14 presents the impulse measured on the wall for one test of each configuration and Table 3 gives the maximum impulse values obtained for all tests. The results were similar to those observed for overpressure. 
Table 2. Initial overpressure collected by three sensors (control, inserted into the wall and laid on the ground) for all experiments. The attenuation of the overpressure measured on the wall relative to the mean value obtained by the reference tests (no plate) is also given. Overpressure ground 1 and overpressure ground 2 correspond to the maximum value of the first and the second peak, respectively.

\begin{tabular}{|c|c|c|c|c|c|}
\hline Experiment Type & $\begin{array}{l}\text { Overpressure } \\
\text { Control (Bar) }\end{array}$ & $\begin{array}{l}\text { Overpressure } \\
\text { Wall (Bar) }\end{array}$ & Attenuation (\%) & $\begin{array}{l}\text { Overpressure } \\
\text { Ground } 1 \text { (Bar) }\end{array}$ & $\begin{array}{l}\text { Overpressure } \\
\text { Ground } 2 \text { (Bar) }\end{array}$ \\
\hline no plate & 0.90 & 2.53 & - & 3.20 & - \\
\hline no plate & 0.89 & 2.61 & - & 3.22 & - \\
\hline no plate & 0.89 & 2.70 & - & - & - \\
\hline 2 expanded metal & 0.90 & 1.05 & 60 & 3.08 & 2.12 \\
\hline 2 expanded metal & 0.86 & 0.88 & 66 & 2.26 & 1.96 \\
\hline 2 expanded metal & 0.89 & 0.99 & 62 & 3.31 & 2.14 \\
\hline 2 expanded metal \& water & 0.89 & 0.90 & 66 & 1.88 & 1.89 \\
\hline 2 expanded metal \& water & 0.78 & 0.68 & 74 & 3.17 & 1.83 \\
\hline 1 expanded metal & 0.89 & 1.42 & 46 & 3.16 & - \\
\hline 1 expanded metal & 0.82 & 1.78 & 32 & 3.52 & - \\
\hline 1 expanded metal & 0.84 & 1.40 & 47 & 3.62 & - \\
\hline 1 expanded metal \& water & 0.80 & 0.82 & 69 & 2.80 & - \\
\hline 1 expanded metal \& water & 0.76 & 0.75 & 71 & 3.08 & - \\
\hline
\end{tabular}

Table 3. Maximum impulse collected by the three sensors (control, inserted into the wall and laid on the ground) for all experiments. The attenuation of impulse measured on the wall relative to the mean value obtained by the reference tests (no plate) is also given. Impulse ground 1 and impulse ground 2 correspond to the maximum value of the first and the second peak, respectively.

\begin{tabular}{|c|c|c|c|c|c|}
\hline Experiment Type & $\begin{array}{l}\text { Impulse Control } \\
\text { (Bar·s) }\end{array}$ & $\begin{array}{l}\text { Impulse Wall } \\
\text { (Bar.s) }\end{array}$ & $\begin{array}{c}\text { Attenuation } \\
(\%)\end{array}$ & $\begin{array}{c}\text { Impulse Ground } \\
1 \text { (Bar.s) }\end{array}$ & $\begin{array}{c}\text { Impulse Ground } \\
2 \text { (Bar.s) }\end{array}$ \\
\hline no plate & 0.00103 & 0.00247 & - & 0.001427 & - \\
\hline no plate & 0.00105 & 0.00275 & - & 0.001388 & - \\
\hline no plate & 0.00097 & 0.00261 & - & - & - \\
\hline 2 expanded metal & 0.00108 & 0.00105 & 60 & 0.001384 & 0.002338 \\
\hline 2 expanded metal & 0.00108 & 0.00105 & 60 & 0.001287 & 0.002258 \\
\hline 2 expanded metal & 0.00105 & 0.00095 & 64 & 0.001127 & 0.001849 \\
\hline 2 expanded metal \& water & 0.00104 & 0.00077 & 71 & 0.001312 & 0.002546 \\
\hline 2 expanded metal \& water & 0.00098 & 0.00071 & 73 & 0.001143 & 0.002234 \\
\hline 1 expanded metal & 0.00107 & 0.00155 & 41 & 0.001411 & - \\
\hline 1 expanded metal & 0.00100 & 0.00144 & 45 & 0.001395 & - \\
\hline 1 expanded metal & 0.00096 & 0.001437 & 45 & 0.001289 & - \\
\hline 1 expanded metal \& water & 0.00094 & 0.00108 & 58 & 0.001418 & - \\
\hline 1 expanded metal \& water & 0.00093 & 0.00110 & 58 & 0.001402 & - \\
\hline
\end{tabular}

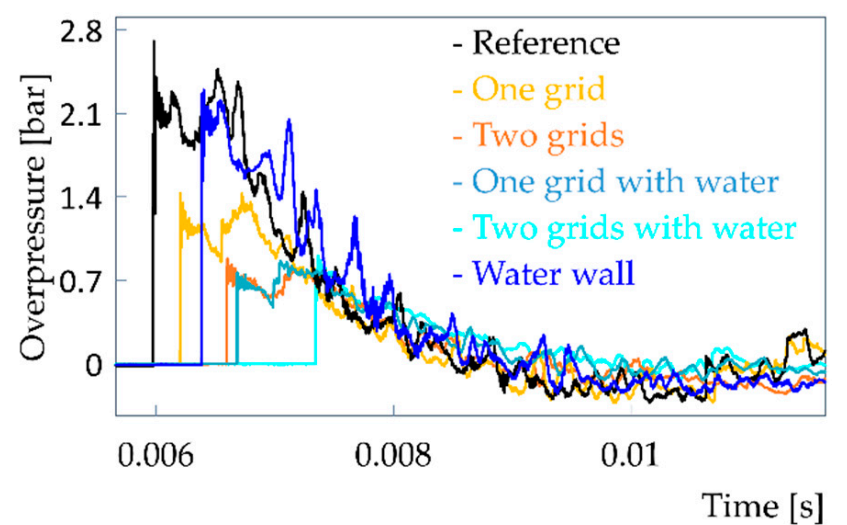

Figure 13. Reflected pressure measured on the wall for one test of each configuration. One reference test is also shown. 


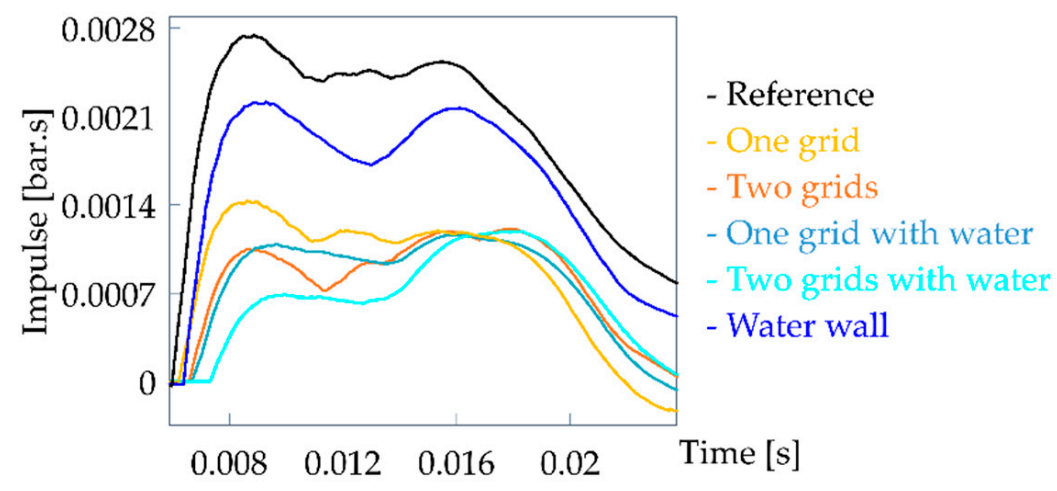

Figure 14. Reflected impulse measured on the wall for one test of each configuration. One reference test is also shown.

Figure 15 presents the overpressure measured by the gauge positioned on the ground at the first plate's position. The reflection of the shock wave, when a plate was placed near this sensor (two-plate configuration), could be observed (see the arrows in the Figure 15). In case of one-plate configurations, the sensor was placed further off the plate and the shock wave reflection was not perceptible. In the case of two-plate configurations, the reflection of the shock wave on the second plate was clearly manifested as a huge overpressure second peak.

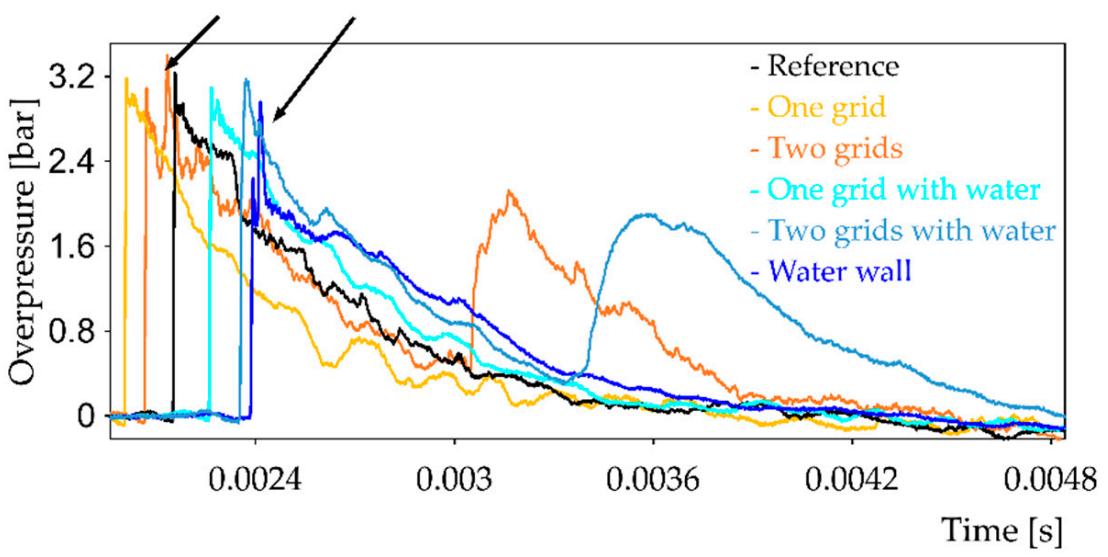

Figure 15. Overpressure obtained by the gauge laid on the ground for one test of each configuration. One reference test is also shown.

\section{Discussion}

Shock wave propagation through one or two deployed metal plate(s) was observed thanks to the EDST and a retroreflective shadowgraph technique. This experimental set-up was very well suited to this research, since the shock wave interaction with perforated plates could be assessed with high loading and visualized at the same time. This is not possible when using a conventional shock tube, the blast loading being rather moderate. In any event, it is not possible to use high Mach numbers when the air flow in the shock tube is especially blocked, due to risk of damage. Understanding of the complex flow field induced by blast that passes through a complex media is an important aspect in blast mitigation research and could help to design new devices for protection against blast loading. The shock wave, when it passed through the apertures of a deployed metal plate, split into several shock waves, one for each aperture, which recombined further on. A complex structure of turbulence appeared just behind the grid and it persisted for some time. The remaining shock wave, which did not pass through the grid, was reflected by the grid. In the case of two plate configurations, the shock wave had time to reform between the two plates, which impacted the second plate. Once again, a part of the shock wave was transmitted and part was reflected. Turbulence behind the second plate was also visible. 
The shock wave reflection and the creation of turbulence led to a blast wave attenuation. Consequently, when two plates served as an obstacle, these phenomena occurred twice and the mitigation was greater. This was confirmed by the reflected overpressure and impulse measured by the sensor inserted into the wall behind the plate(s). When the number of plates increased, these values were reduced. Similar observations were made by $\mathrm{O}$. Ram et al. [13], who assessed the propagation of shock waves through an array of perforated plates in a conventional shock tube. Thus, we can conclude that similar phenomena occurred at low ( 3 bar) and high loading ( 20 bar).

The results obtained in free field were consistent with the results obtained by means of the EDST. The reflected overpressure and impulse measured behind one plate on a wall was reduced ion the order of $32-47 \%$. The addition of a second plate on the shock wave path led to a stronger attenuation (62-66\%). When a water film was used, the reflected overpressure on the wall was reduced still more, especially in the case of one-plate configurations-the mitigation approached that obtained from two-plate configurations. The water cover had only a small effect on blast mitigation when two plates were used. We can conclude that the water layer's contribution mostly enhanced the reflection of the shock wave by filling the apertures with water. When one perforated plate was covered with a water film, its capacity to reflect the blast wave was enhanced, its performance to mitigate the blast increased and approached that obtained from two-plate configurations. In cases with two plates, the obstruction of the blast wave was rather high, and the addition of a water cover induced only a modest improvement. In [7], thanks to a transonic shock tube, the interaction of a blast wave with a perforated plate with a water cover was imaged and it was observed that the water film disintegrated into droplets significantly after the shock wave front had passed through it. The fragmentation of the water film had little effect on the attenuation, as it broke long after the passage of the shock wave front and there is little extraction of energy from the shock front from water layer fragmentation. In this work, the results have also shown that a water wall alone had almost no impact on the reflected overpressure on the wall. Moreover, the study [4] on blast mitigation using a water wall, in which walls made of plastic bags, filled with water and having a thickness of 5 to $8 \mathrm{~cm}$, it was shown that the mitigation was obtained by obstruction, reflection and diffraction of the blast wave. The mitigation mechanism was comparable to that of a rigid wall, thus the mitigating effect of energy exchange with water was not primarily responsible for the effect. The results obtained here could also be compared to those obtained by Gebbeken et al. [6] and Xiao et al. [5]. In these two studies, blast mitigation observed when using a single grid was very low and this could be explained by the high porosity of the grids used. Indeed, the first study [6] used a stainless steel ring mesh with a porosity of $63 \%$ and, in the second, a woven wire mesh having a relative opening fraction of $60.2 \%$. In the setup using ring mesh, adding a water curtain also enhanced the attenuation of both peak overpressure and positive impulse. The authors also claimed that when a blast wave hits ring mesh covered by water, the water layer forms a closed surface that reflects the blast wave to a greater extent.

In the case of a higher-charge explosive, the phenomenon of shock wave transmission/reflection would likely be the same and equivalent mitigation performance would be achieved. However, if the grids are not sufficiently resistant to a high loading, the grids could deform and tear. Some debris could impact the structure behind such grids, and consequently the use of gridded plates could have prejudicial effects. The grids and their attachment system must be sized to guarantee their resistance and their structural integrity with respect to anticipated blast size.

\section{Conclusions}

In this paper, we have assessed a blast mitigation solution made of perforated plates with or without a water cover. The mitigation of a blast wave after its passage through one or two plate(s) made of deployed metal, covered or not by a water film, was investigated. First, we imaged the interaction of a blast wave with the grids at high loading. Secondly, 
free-field air blast experiments were performed in order to evaluate the protection system under real conditions. It was observed that the overpressure and the impulse downstream of the grids were reduced and that the mitigation performance increased with the number of plates. Adding a water layer to one grid contributed to its mitigation capacity. However in setups with two plates, the addition of a water cover on the first grid induced only a modest improvement. All in all, this method seems to warrant interest for protection purposes.

Author Contributions: Conceptualization, methodology, experimentations, data analysis, writing, review and editing-T.S. Metrology, methodology, experimentations, data analysis-D.E. Both authors have read and agreed to the published version of the manuscript.

Funding: This research received no external funding.

Institutional Review Board Statement: Not applicable.

Informed Consent Statement: Not applicable.

Data Availability Statement: The data are provided in the paper.

Acknowledgments: We thank our colleagues Yannick Boehrer, Thierry Ottié, Yannick Stehlin and Sylvain Hemmerlin who assisted us in our research by providing technical support.

Conflicts of Interest: The authors declare no conflict of interest.

\section{References}

1. Kingery, C.; Pearson, R.; Coulter, G. Shock Wave Attenuation by Perforated Plates with Various Hole Sizes. USA Ballistic Research Laboratory Memorandum Report; 1977; $\mathrm{n}^{\circ}$ 2757, Defense Technical Information Center. Available online: https: / /apps.dtic.mil/sti/citations/ADA041854 (accessed on 18 June 2021).

2. Britan, A.; Karpov, A.V.; Vasilev, E.I.; Igra, O.; Ben-Dor, G.; Shapiro, E. Experimental and numerical study of shock wave interaction with perforated plate. J. Fluids Mech. 2004, 126, 399-409. [CrossRef]

3. Britan, A.; Igra, O.; Ben-Dor, G.; Shapiro, E. Shock wave attenuation by grids and orifice plates. Shock Waves 2006, 16, 1-15. [CrossRef]

4. Chen, L.; Zhang, L.; Fang, Q.; Mao, Y.-M. Performance based investigation on the construction of anti-blast water wall. Int. J. Impact Eng. 2015, 81, 17-33. [CrossRef]

5. Xiao, W.; Andrae, A.; Gebbeken, N. Experimental investigations of shock wave attenuation performance using protective barriers made of woven wire mesh. Int. J. Impact Eng. 2019, 131, 209-221. [CrossRef]

6. Gebbeken, N.; Rüdiger, L.; Warnstedt, P. Explosion mitigation by water mist-ring mesh with water curtain. In Proceedings of the 25th MilitaryAspects of Blast and Shock Conference, Hague, The Netherlands, 23-25 September 2018.

7. Schunck, T.; Bastide, M.; Eckenfels, D.; Legendre, J.-F. Explosion mitigation by metal grid with water curtain. Shock Waves 2021. [CrossRef]

8. Seeraj, S. Shock Wave Interactions with Porous Plates. Master's Thesis, University of the Witwatersrand, Johannesburg, South Africa, 2007.

9. Louar, M.A.; Belkassem, B.; Ousji, H.; Spranghers, K.; Kakogiannis, D.; Pyl, L.; Vantomme, J. Explosive driven shock tube loading of aluminium plates: Experimental study. Int. J. Impact Eng. 2015, 86, 111-123. [CrossRef]

10. Ousji, H.; Belkassem, B.; Louar, M.A.; Reymen, B.; Martino, J.; Lecompte, D.; Pyl, L.; Vantomme, J. Air-blast response of sacrificial cladding using low density foams: Experimental and analytical approach. Int. J. Mech. Sci. 2017, 128-129, 459-474. [CrossRef]

11. Stojko, S.; Freundt, J.; Anderson, J.G.; Delaney, T. Experimental characterization of the interaction of blast waves from multiple high explosive charges. In Proceedings of the 25th MilitaryAspects of Blast and Shock Conference, Hague, The Netherlands, 23-25 September 2018.

12. Kingery, C.N.; Bulmash, G. Technical Report ARBRL-TR-02555: Air Blast Parameters from TNT Spherical Air Burst and HEMISPHERICAL Burst; AD-B082 713; U.S. Army Ballistic Research Laboratory: Aberdeen Proving Ground, MD, USA, 1984.

13. Ram, O.; Ben-Dor, G.; Sadot, O. On the pressure buildup behind an array of perforated plates impinged by a normal shock wave. Exp. Therm. Fluid Sci. 2018, 92, 211-221. [CrossRef] 